\title{
0 reconhecimento no Estado Democrático de Direito: perspectivas da filosofia de Habermas para efetividade da Democracia e dos Direitos Humanos ${ }^{1}$
}

Recognition in the democratic state: perspectives from Habermas'
philosophy effectiveness of Democracy and Human Rights

Luciano Braz Silva²

\begin{abstract}
Resumo:
Pretendendo fazer uma releitura dos pressupostos de validade do direito, esse artigo, toma como campo de pesquisa o mundo da vida interpretado como esfera dos discursos, dos diálogos interpelativos, e do exercício democrático. Essa estrutura reflete-se no modo característico da validade jurídica que limita a facticidade da execução judicial estatal com a legitimidade de uma positivação jurídica que reivindica um procedimento racional.
\end{abstract}

Palavras-chave: dignidade humana, reconhecimento, emancipação, razão comunicativa.

\begin{abstract}
:
Intending to reconsider the validity of the assumptions of law, this article takes as a research field of life interpreted the world as a sphere of speeches, dialogues interpelativos, and the democratic exercise. This structure is reflected in the characteristic way of limiting the legal validity of facticity judicial foreclosure state with the legitimacy of a legal positivization claiming a rational procedure.
\end{abstract}

Keywords: human dignity, recognition, emancipation, communicative reason.

\section{INTRODUÇÃO}

A proposta deste artigo visa a apontar algumas características diagnosticadas na atual sociedade contemporânea que descrevem tipos de complexidades existentes na esfera social regulada pelos sistemas integradores. À vista dos sistemas sociais que integram o mundo da vida, a sociedade moderna, marcada pelo pluralismo, multiculturalismo e, sobretudo, pela a complexidade emergente, revela-se no papel preponderante do direito, no que diz respeito à sua função social integradora e reguladora. Dada perspectiva, entende-se que o direito funciona como

\footnotetext{
${ }^{1}$ Artigo submetido em 11 de abril de 2013 e aceito em 13 de novembro de 2013.

${ }^{2}$ Advogado. Mestre em filosofia do direito pelo Centro Universitário Eurípides de Marília (UNIVEM ), com Bolsa Capes. Graduado no Curso de Direito do Univem. Bolsista pela FAPESP / Iniciação Científica 2008 - 2009 com deferimento de renovação para 2010. Diretor do Diretório Acadêmico do Curso de Direito do Univem 2008. Graduado no ano de 2004 no curso de Teologia pelo I.B.E.S. Integrante do Grupo de Pesquisa Científicas GEP - Univem. Email: brazadvogadoluciano@gmail.com
} 
um instrumento que regula e integra o mundo social, bem como as relações que ocorrem nesse campo.

O artigo trará para o campo das discussões teóricas a proposta de Jürgem Habermas fundamentada no plano da razão comunicativa. Veremos que, a partir das proposições lógicas inseridas no contexto de fala, os sujeitos, na qualidade de falantes e ouvintes, tentam ajustar - a partir dum acordo de fala racional - interpretações comuns, formuladas com o foco no contexto da fala e com a finalidade de harmonizar entre si seus respectivos planos, via processo de entendimento, pelo caminho de uma busca incondicionada de fins ilocucionários. Com isso, Habermas pretende demonstrar como a tensão entre facticidade e validade - inerente à linguagem - está pragmaticamente interligada (simbiose) com a integração de indivíduos socializados comunicativamente. 0 mundo da vida em comum continua a ser, para os intervenientes, como um pano de fundo intuitivamente conhecido, não problemático, indesmembrável e holístico.

Utilizando alguns preceitos filosóficos hegelianos, autores como Taylor e Honneth ressaltam a construção relacional da identidade, frisando as estruturas dialogais entre os sujeitos que lutam o tempo todo por reconhecimento mútuo. Tanto Taylor como Hanneth entendem que essa será a condição pela qual os sujeitos podem se desenvolver de maneiras saudáveis e autônomas. Nessa perspectiva, a compreensão e o reconhecimento da identidade (por si e pelo outro) seria a condição primeva para autorrealização. Em seu ensaio seminal sobre 0 multiculturalismo, Taylor afirma que o reconhecimento não é uma questão de cortesia, antes sim, trata-se de uma necessidade humana. Isso porque pessoas e grupos podem sofrer danos reais se a sociedade os representa com imagens restritivas e depreciativas.

0 artigo apresentará algumas considerações de Honneth que se coadunam ao pensamento de Jügen Habermas. Para Honneth, o mundo transforma e evolui-se moralmente por meio das lutas intersubjetivas por reconhecimento mútuo. É no mundo da vida que se naturalizam e se questionam tradicionais padrões de comportamento (desrespeito). Desse modo, indivíduos buscam, diariamente, fazer-se reconhecidos para se autorrealizarem enquanto sujeitos de direito. A questão da distribuição é pensada por Honneth a partir de um modelo diferenciado de reconhecimento. Como já abordado, ele alega que os sujeitos lutam por bens materiais tanto para se verem considerados seres humanos de igual valor, como para verem reconhecidos seus méritos 
e realizações distintivos. É a partir da lógica do reconhecimento, e não simplesmente visando ao aumento de bens materiais, que os sujeitos aspirariam a práticas redistributivas. Interessa-nos frisar aqui, exatamente, a importância desse uso ético.

Numa retomada da teoria do agir comunicativo, Habermas passa a considerar seriamente as possibilidades do dissenso numa prática comunicativa. Tal risco se mostra muito evidente, analisando o fato da complexidade que envolve a sociedade moderna multicultural, em que as interações estratégicas são costumeiramente utilizadas pelos sujeitos. 0 direito passa, então, a ser visto como resposta adequada ao presente questionamento. Ao perceber que a linguagem, mesmo quando utilizada comunicativamente, não tem força suficiente para assegurar a integração social, devido ao multiculturalismo e às complexidades ideológicas que envolvem a sociedade moderna, torna praticamente impossível estabelecer uma base comum para regularização das questões problematizadas. Habermas aponta o direito como meio adequado para preencher esse déficit estabilizador social. Isso porque o direito moderno positivado se apresenta com a pretensão à fundamentação sistemática, à interpretação obrigatória e à imposição ${ }^{3}$ - que institucionaliza (atribui validade) as pretensões de verdade (assertivas) que surgem na esfera pública -, com sua força impositiva que alcança todos, indistintamente, que estejam submetidos a sua ordem legal.

\section{A LINGUAGEM E O DIREITO: tensão entre facticidade e validade}

Na sociedade moderna, mormente os sistemas sociais, de forma objetiva, tendem a regularizar os fatos que surgem no mundo da vida e, para tanto, impõem exigências que visam a prover a manutenção das ordens sociais então existentes. Característica da sociedade moderna, os sistemas sociais apontam dois atores que dividem o protagonismo a tal fim que, desde o século passado, vem contribuindo, consideravelmente, para a colonização do mundo da vida.

Dadas as figuras predominantes da política e do mercado, o sistema econômico, destacado pelos liberais, confronta-se com objetivos e ideologias traçados pelos socialdemocratas, os quais buscam compensar a preponderância econômica com as intervenções do sistema político. A proposta fomentada pela escola do liberalismo aponta para uma competição de mercado livre e independente, como fator de regulação social, o que, por conseguinte, resulta

${ }^{3}$ HABERM AS, Jürgen. Era das transições. Rio de Janeiro: Tempo Brasileiro, 2003, p. 110. 
em desigualdades materiais entre os indivíduos, assim como na monopolização e na duradoura crise da economia de mercado. No entanto, a proposta trazida pelos ideários do estado de bemestar social, que buscam concretizar no mundo da vida - por meio do controle de mercado - a igualdade material fomentada pela intervenção do sistema político no mundo da vida, não obstante os desarranjos e transtornos burocráticos a serem resolvidos. 0 Estado liberal e o Estado de bem-estar confrontam-se reciprocamente, o que, de certa forma, prejudica, desestabilizando a manutenção da ordem social no seu todo e, por conseguinte, faz suscitar, no espírito da sociedade, uma descrença a uma possível estabilidade social. Dada descrição da sociedade moderna, o médium do direito apresenta-se como um instrumento - especialmente na figura moderna do direito positivo - de colonização do mundo da vida, na medida em que as relações sociais cotidianas e familiares estão, a cada dia, mais impregnadas pela "juridificação"4

As discussões em torno do conceito de direito, de sistema de direitos e de Estado Democrático de Direito permitiram inserir um elemento intermediário entre a solidariedade da ação comunicativa no mundo da vida e a instrumentalidade dos sistemas que operam estrategicamente. Destarte o direito, via sistema jurídico, representa o instrumento pelo qual opera o intercâmbio entre o mundo da vida e os sistemas, bem como entre ação comunicativa e estratégica. A partir do conceito do agir comunicativo - em que encontramos forças ilocucionárias da linguagem orientada ao entendimento - podemos visualizar - no próprio conceito - sua função peculiar e necessária à coordenação da ação. Para Habermas, a tensão entre facticidade e validade, que se introduz no próprio modo de coordenação da ação, coloca exigências elevadas para a manutenção de ordem social. Portanto, torna-se indiscutível que, tanto o mundo da vida, como também, as instituições que surgem naturalmente e o próprio direito, têm que aniquilar as instabilidades de um tipo de socialização que se estrutura e se realiza com as tomadas de posição em termos de sim e de não, que seguem instauradas em face de pretensões de validade criticáveis ${ }^{5}$.

Característica das sociedades modernas econômicas, esse problema geral se torna premente, sobretudo, pelo revestimento normativo das interações estratégicas não abarcadas

${ }^{4}$ DURÃO, Aylton Barbieri. A tensão interna entre facticidade e validade no direito segundo Habermas. Marília: Oficina Universitária Unesp, 2008. p. 15.

${ }^{5}$ HABERM AS, Jürgen. Direito e democracia: entre facticidade e validade. Rio de Janeiro: Tempo Brasileiro. 2003, p. 25-26. 
pela eticidade tradicional. Isso explica, de um lado, a estrutura e o sentido de validade de direitos subjetivos e, de outro lado, as conotações idealistas de uma comunidade jurídica que, enquanto associação de cidadãos livres e iguais, determina por si mesma as regras de sua convivência.

À vista dos sistemas sociais que integram o mundo da vida, a sociedade moderna, marcada pelo pluralismo, multiculturalismo e, sobretudo, pela a complexidade emergente, revelase no papel preponderante do direito, no que diz respeito à sua função social integradora. Dada perspectiva, entende-se que o direito funciona como um instrumento que regula e integra 0 mundo social, bem como as relações que ocorrem nesse campo. Dado seu caráter transformador atuante no campo das reivindicações suscitadas no mundo da vida - comumente expressas em linguagens habituais do cotidiano, segundo a racionalidade comunicativa e a racionalidade estratégica dos sistemas sociais -, o direito oferece aos sujeitos duas vias que podem ser utilizadas a pretexto da finalidade das suas reivindicações. Por um lado, temos a figura da solidariedade da ação comunicativa atuante no mundo da vida; por outro, temos a figura da lei que, mediante seu poder coercitivo, regula as ações dos sujeitos que atuam na esfera do mundo social. Considerando a função social integradora que o direito exerce, a mesma não pode ser realizada tão somente pelo entendimento inerente ao mundo da vida, tampouco pelos sistemas funcionais reguladores, sobretudo pelo o sistema econômico e político especializado na racionalidade estratégica. Habermas vê, na figura do direito positivo moderno, a possibilidade de assimilar - via ação comunicativa - a tensão entre facticidade e validade. À vista de tal possibilidade, Habermas busca se envolver com o problema central que abarca as possibilidades de reprodução social, à luz das pretensões de validade. A explicação poder-se-ia apresentar a partir do direito moderno, no qual:

(...) uma vez que, segundo sua mediação, faz-se possível o surgimento de comunidades artificiais, comunidades jurídicas (sociedades mercantis, Estados federativos, comunidades internacionais, etc.), que, por sua vez, se compõem de membros livres e iguais, cuja sociabilidade resulta de uma pretensa ameaça de sanção e da suposição de um acordo racional a lhe dar fundamento ${ }^{6}$.

Precisamente, essa é a razão pela qual Habermas considera que o conceito do agir comunicativo atribui às forças ilocucionárias da linguagem, orientada ao entendimento, a função importante da coordenação da ação. Os atos ilocucionários trazem, em seu bojo, por meio da

\footnotetext{
${ }^{6}$ M OREIRA, Luiz. Fundamentação do direito em Habermas. Belo Horizonte: Mandamentos, 1999, p. 113.
} 
força comunicativa do enunciado, a execução de uma ação; daí, conclui-se a vinculação entre agir comunicativo e a força dos atos ilocucionários da qual, a partir desse patamar, se poderá delinear uma nova relação entre facticidade e validade por meio do médium linguístico ${ }^{7}$.

Não obstante a transição da razão prática para a ação comunicativa possa significar uma ruptura com a tradição normativa, a filosofia de Habermas não descarta as preocupações de ordem fundamental que tratam dos problemas que assolam o mundo da vida. Por um lado, temos a estrutura e o sentido de validade dos direitos subjetivos; por outro, temos as conotações idealistas de uma comunidade jurídica (ideal de fala) e, por tratar-se de uma associação constituída por cidadãos livres e iguais, essa comunidade determina, por si mesma, as regras de sua convivência. Ora, a sociedade moderna, dentre outras características que Ihes são peculiares, traz destacado, em sua identidade, o multiculturalismo ideológico pluralista, o que suscita indagações quanto à possibilidade (ou não) de se coordenar, entre si, os planos de ações dos vários sujeitos, de tal modo que as ações de um partido (atores) possam estar atreladas (relacionadas) nas práticas do outro. Habermas considera que o possível entrelaçamento contínuo reduz o jogo das possibilidades de escolha, duplamente contingente, a uma medida que possibilita o entrelaçamento menos conflituoso possível de intenções e ações, portanto o surgimento de padrões de comportamento e da ordem social no geral. A par disso, temos, ainda, a tarefa de esclarecer a questão de como a razão comunicativa faz a mediação com os fatos sociais e, mais ainda, em que sentido a razão comunicativa poderia incorporar-se aos fatos sociais? Fugindo ao risco de não confundir razão e realidade, Habermas procura demonstrar que a tensão entre facticidade e validade, inerente à linguagem, migra desta para o direito; enquanto a linguagem é utilizada apenas como médium para transmissão de informações e redundâncias, a coordenação ocorre por meio da influenciação recíproca de atores que agem uns sobre os outros de modo funcional. Portanto, tão logo, porém, as forças ilocucionárias das ações de fala assumem um papel coordenador da ação, a própria linguagem passa a ser explorada como fonte primária da integração social. É nisso que consiste 0 agir comunicativo ${ }^{8}$.

A partir das proposições lógicas inseridas no contexto de fala, os sujeitos, na qualidade de falantes e ouvintes, tentam ajustar - a partir dum acordo de fala racional - interpretações

\footnotetext{
${ }^{7}$ Ibidem, p. 114.

${ }^{8}$ HABERMAS, Jürgen. Direito e democracia: entre facticidade e validade. Rio de Janeiro: Tempo Brasileiro. 2003, p. 36.
} 
comuns, formuladas com o foco no contexto da fala e com a finalidade de harmonizar entre si seus respectivos planos, via processo de entendimento, pelo caminho de uma busca incondicionada de fins ilocucionários. Sendo assim, no instante que os sujeitos de fala suspendem o enfoque objetivador de um observador e de um agente interessado imediatamente no próprio sucesso, e passam a incorporar um enfoque performativo de um falante que busca se entender como uma segunda pessoa sobre algo no mundo, as energias de ligação da linguagem podem ser impulsionadas (mobilizadas) para a coordenação de planos de ação. Partindo dessas proposições lógicas de atos de fala, exposições ilocucionárias de atos de fala podem visar a um efeito performativo na ação, ou seja, da resposta afirmativa do destinatário a uma oferta séria, consequentemente, resultam obrigações que se tornam relevantes para as consequências da ação. Surge, assim, a vinculação entre agir comunicativo e a força dos atos ilocucionários e, a partir dessas premissas, poderá se delinear uma nova relação entre facticidade e validade por meio do médium linguístico. M uito embora a migração da razão prática para a ação comunicativa possa representar uma ruptura com a tradição normativista, os problemas que desestabilizam 0 mundo da vida não foram ignorados por Habermas, isto é, o filósofo procurou considerar como ordem fundamental tais problemas. Vejamos que, com a colocação do problema da idealização inevitável realizada pela linguagem, idealização que se dá com o entendimento mútuo, surge 0 perigo de confundir razão e realidade. Sendo assim, dado o fato da razão comunicativa estar adscrita às realidades sociais, devemos responder à questão de como se dará a mediação entre razão comunicativa e fatos sociais ou, em que sentido, a razão comunicativa poderia incorporar-se aos fatos sociais ${ }^{9}$.

Ao que nos parece, a intenção de Habermas é demonstrar como a tensão entre facticidade e validade, inerente à linguagem, migrará desta para o direito. Esse problema suscitado, no contexto do século XX, dá-se com a recusa da resposta psicológica aos problemas lógicos e matemáticos e aqueles pertencentes à gramática:

A partir do momento em que as ideias sobre a oposição abstrata entre 0 inteligível e o fenomenal, que serviam de pano de fundo à metafísica kantiana, não convenciam mais ninguém e, a partir do momento em que o entrelaçamento especulativo e dialético entre as esferas da essência e da aparência, criado por Hegel, perdeu sua plausibilidade, entraram em cena, no decorrer do século XIX,

${ }^{9}$ Ibidem, p. 27. 
interpretações empiristas que passaram a dar preferência a uma explicação psicológica das relações lógicas ou conceituais: contextos de validade foram assimilados a processos fáticos de consciência. Contra tal psicologismo levantaram-se, utilizando quase sempre os mesmos argumentos, Ch. S. Peirce, na América, Gottlob Frege e Edmund Husserl, na Alemanha, e G. E. M oore e B. Russel na Inglaterra. E, ao se recusarem a tomar a psicologia como base para a lógica, a matemática e a gramática, eles lançaram as bases para a filosofia do século XX ${ }^{10}$.

Para Habermas, esse movimento encontra-se resumido na tese de Frege, ao se procurar diferenciar pensamento e representação. A crítica à opinião, segundo a qual 0 pensamento não é mais do que consciência representadora, repousa nessa consideração simples. Nas representações, o que temos tão somente são os objetos, sendo que, por outro lado, estado de coisas ou fatos é apreendido em pensamentos. Logo, pensamentos e fatos devem ser mediados no mundo dos objetos representáveis, de modo a tornar-se possível o aprendizado; eles só são acessíveis (pensamentos e fatos) enquanto representados em estados de coisas expressos por meio de proposições.

Os pensamentos - dado o fato de ultrapassarem os limites de uma consciência individual - articulam-se por meio de proposições assertivas e torna-se, então, possível lermos a estrutura dos pensamentos observando a estrutura das proposições, consideradas por Habermas, como partes elementares de uma linguagem gramatical passível de verdade. Nisso, consiste a tese habermasiana de que as expressões linguísticas tenham significado idêntico para os mais diversos usuários. Dessa forma, certamente, em uma dada comunidade de linguagem ocorrerá uma mesma compreensão sobre uma certa expressão gramatical. Nas mais diversas situações em que são empregadas, essas expressões conservam o mesmo significado. Isso quer dizer que, ao serem empregadas, as expressões compartilham de uma certa transcendência que lhes é peculiar ${ }^{11}$. Na prática, Habermas considera que, necessariamente, os membros de determinada comunidade de linguagem devem considerar que falantes e ouvintes podem compreender uma expressão gramatical de modo idêntico. Para tanto, devem julgar que as mesmas expressões conservam igual significado independente da variedade de situações e dos atos de fala nos quais são empregadas. Assim,

\footnotetext{
${ }^{10}$ HABERM AS, Jürgen. Direito e democracia: entre facticidade e validade. Rio de Janeiro: Tempo Brasileiro. 2003, p. 27.

${ }^{11}$ M OREIRA, Luiz. Fundamentação do direito em Habermas. Belo Horizonte: Mandamentos, 1999, p. 116.
} 
A idealidade, apoiada em sinais linguísticos e regras gramaticais, caracteriza um pensamento geral, idêntico consigo mesmo, aberto e acessível, algo transcendente em relação à consciência individual, não se confundindo com as representações particulares, episódicas, acessíveis apenas privadamente ou imanente à consciência ${ }^{12}$.

A partir desse raciocino lógico gramatical, são concebidas regras que emprestam formas determinadas a eventos linguísticos, numa relação fonética, sintática e semântica, reconhecível e solidificada por meio das variações. No tocante a isso, consiste a relação entre o geral e o particular, ou, seguindo a tradição, entre essência e aparência. Sendo assim, a idealidade pressuposta no pensamento aponta a generalidade que se faz transcender à consciência individual, ao que, por conseguinte, não obstante a variedade de vozes abertas e acessíveis existentes no mundo de fala preserva-se um elo condutor opondo-se ao acesso das representações de uma consciência individual particular solipsista.

\section{UM A POLITICA DO RECONHECIM ENTO: o debate entre Taylor, Honneth e Habermas}

As considerações de Amy Gutmann, que nos é apresentada por Habermas, aponta que o reconhecimento público pleno conta com duas formas de respeito, a saber: 1) o respeito pela identidade individual de cada indivíduo, o que significa dizer que esse respeito independe de sexo, raça ou procedência étnica; e 2) o respeito pelas formas de ação, pelas práticas e visões peculiares de mundo que gozam de prestígio junto aos integrantes de grupos desprivilegiados ou que estão intimamente ligados a essas pessoas. Nessa perspectiva, as exigências que são colocadas, objetivamente, não visam a estabelecer, em primeira linha, um status que asseguraria um padrão isonômico de condições sociais de vida; antes, o que se busca, em primeira mão, seria a defesa da integridade de formas de vida e tradições com as quais os membros de grupos discriminados - de modo próprio - identificam-se. O não reconhecimento de grupos sociais soa como uma dissonância cultural segregativa que marginaliza alguns grupos previamente rotulados; origina-se e mantém-se tão somente com as condições ingeridas de demérito social, de modo que, o não reconhecimento cultural e o demérito social se fortalecem de maneira cumulativa ${ }^{13}$.

\footnotetext{
${ }^{12}$ HABERM AS, Jürgen. Direito e democracia: entre facticidade e validade. Rio de Janeiro: Tempo Brasileiro. 2003, p. 29.

${ }^{13}$ HABERM AS, Jürgen. A inclusão do outro: estudos de teoria política. São Paulo: Loyola. 2007, p. 239.
} 
Charles Taylor considera que, dado o fato de que o asseguramento de identidades coletivas possa concorrer com o direito a liberdades subjetivas iguais - com o direito humano único e original, na concepção kantiana -, o que configuraria uma área de colisão entre ambos, certamente, a partir do caso concreto, dever-se-ia decidir sobre a precedência de um ou outro. A reflexão que segue exposta depõe em favor disso:

(...) já que a exigência 2 exige a consideração de particularidades das quais a exigência 1 parece abstrair, o princípio de tratamento equitativo deve alcançar validação nas políticas concorrentes - em uma política de respeito por todas as diferenças, por um lado, e em uma política de universalização de direitos subjetivos, por outro. Uma política deve compensar as desvantagens do universalismo uniformizante que a outra ocasiona ${ }^{14}$.

Em seu ensaio seminal sobre 0 multiculturalismo, Taylor ${ }^{15}$ entende que 0 reconhecimento não se trata de algo oriundo de uma cortesia, antes de tudo, trata-se da necessidade humana. Portanto, isso significa dizer que, pessoas e grupos podem - de certa forma sofrerem danos consideráveis se a sociedade os identifica com imagens restritivas e depreciativas. Para Taylor por meio das interações intersubjetivas (sejam elas agonísticas ou amistosas) e dialogais os sujeitos passam ser reconhecidos como tais, destarte, eles podem realizar suas originalidades insitas. A propósito, em um mundo que construiu uma imagem individualizada de identidade, consubstanciada pelo princípio de autonomia, uma vez que eu não sou verdadeiro comigo mesmo, consequentemente, eu passo a desconhecer a própria essência da minha identidade (da minha vida); consequentemente, eu passo a ignorar o que o ser humano significa para mim ${ }^{16}$. Essa autonomia só pode ser construída em diálogos - em parte, externos e, em parte, internos - com os outros.

Taylor busca fundamentar seus argumentos teóricos sobre bases histórico-filosóficas, e assim, retoma os alicerces valorativos que delineiam e estruturam a própria existência da sociedade. Desse modo, não seria absurdo pensar, por exemplo, que existem hierarquias valorativas tácitas que transcendem práticas cotidianas e instituições que se apresentam como imparciais, ou neutras, tais como o mercado e o Estado. Ora, vejamos que, a própria configuração dos sujeitos, atrelada às práxis do cotidiano, é regulada por princípios morais, ao que

\footnotetext{
${ }^{14}$ HABERM AS, Jürgen. A inclusão do outro: estudos de teoria política. São Paulo: Loyola. 2007, p. 241.

${ }^{15}$ TAYLOR, C. The Politics of Recognition. Princeton University. 1994, p. 26.

${ }^{16}$ Ibidem, p. 30.
} 
Taylor denomina configurações. Uma "configuração incorpora um conjunto crucial de distinções qualitativas. Pensar, sentir, julgar no âmbito de tal configuração é funcionar com a sensação de que alguma ação ou modo de vida ou modo de sentir é incomparavelmente superior aos

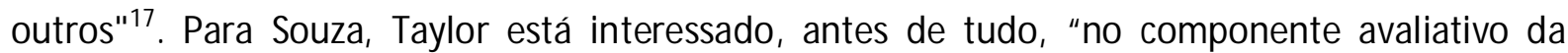
constituição da identidade humana, na medida em que a autointerpretação dos sujeitos passa a ser percebida como momento constitutivo para a construção desta"18.

Em uma espécie de arqueologia ligada à concepção de bem, Taylor pretende encontrar a autocompreensão dos atores com vistas à definição moral da época considerando, essencialmente, a cultura em que esses atores estão inseridos, o substrato das suas identidades ${ }^{19}$. Nessa perspectiva, na contemporaneidade, talvez o mais urgente e poderoso conjunto de exigências que reconhecemos como morais aponta o respeito à vida, à integridade, o bem-estar e mesmo à prosperidade dos outros. Desse modo, a figura da dignidade passa ser compreendida como a sendo a essência mátria do pano de fundo moral que rege as sociedades ocidentais contemporâneas, superestimando a capacidade destas de implementar uma universalização de direitos que naturalize o valor da igualdade ${ }^{20}$. Para o filósofo canadense, na modernidade, houve um declínio da sociedade hierarquicamente predeterminada, o que comprometeu significativamente a honra estamental em direção à dignidade geral. Enquanto a política da dignidade universal rechaçava as formas de discriminação, que eram bastante "cegas" com relação aos modos em que os cidadãos se diferem, a política da diferença, frequentemente, redefine a não discriminação pretendendo com isso ver nas distinções a base do tratamento diferencial. Para Taylor, a busca pelo reconhecimento envolve esses dois tipos de política, buscando no horizonte da consciência da igualdade do valor humano a valorização daquilo que cada um fez a partir dessa igualdade $\mathrm{e}^{21}$.

Para Habermas, tanto Taylor quanto Walzer contestam a ideia de uma suposta neutralidade ética no direito, resultando daí uma expectativa formada sobre os preceitos do Estado de direito que tem como ideal a fomentação ativa de determinadas concepções do bem viver, caso isso se faça necessário. A partir das suas considerações, Taylor sugere um modelo

\footnotetext{
${ }^{17}$ TAYLOR, C. As fontes do self: a construção da identidade moderna. São Paulo: Loyola, 1997, p. 35.

${ }^{18}$ SOUZA, J. Charles Taylor e a teoria crítica do reconhecimento. Brasília: UnB, 2000, p. 97.

${ }^{19}$ SOUZA, J. Uma teoria crítica do reconhecimento. São Paulo: Lua Nova, 2000, p. 137.

${ }^{20}$ M ATTOS, P. Recognition, between Justice and Identity. São Paulo: Lua Nova. 2004, p. 143-160.

${ }^{21}$ TAYLOR, C. The Politics of Recognition. Princeton University. 1994, p. 39.
} 
alternativo que, de acordo com determinadas condições, é possível se pensar em garantias de status restritivas aos direitos fundamentais, desde que essas garantias possam assegurar a sobrevivência de formas de vida cultural, e que assegurem também o exercício de políticas ativamente empenhadas em gerar novos integrantes desses grupos, desde que dedicadas, por exemplo, a que as futuras gerações possam também identificar-se com seus precedentes. Nesse sentido, as compreensões de ordem política que envolvem deliberações, exercício e garantias de direitos fundamentais não estarão preocupadas tão somente com os direitos inerentes às populações já existentes; antes, as reivindicações alcançarão os direitos das populações futuras. Assim, por meio de lutas simbólicas, os sujeitos negociam identidades, buscam reconhecimento próprio e social. Essas lutas, cada vez mais explícitas, transcendem interesses particulares e, seus efeitos, tomam proporções gigantescas por via de protestos públicos que não buscam a simples tolerância ou condescendência, mas o respeito e a valorização do diferente.

Em primeiro lugar, é preciso observar - conforme aponta Habermas - que Taylor torna plausível sua tese da inconciliabilidade ao apresentar sua teoria dos direitos sob um enfoque seletivo de leitura ligado ao liberalismo. A teoria tayloriana, portanto, estabelece seu fundamento sobre o pressuposto de um status equitativo de liberdades de ação subjetivas, em forma de direitos fundamentais, para todos os jurisconsortes. Na hipótese da existência de casos controversos, o tribunal decidirá quais direitos cabem e a quem; assim, o princípio da equidade de direitos para todos "encontra validação tão somente sob a forma de uma autonomia juridicamente apoiada, à disposição do uso de qualquer um que pretenda realizar seu projeto de vida pessoal"22. Essa interpretação atribuída ao sistema de direito é fortemente criticada por Habermas, que a caracteriza como sendo:

(...) paternalista, porque corta pela metade o conceito de autonomia. Ela não leva em consideração que os destinatários do direito só podem ganhar autonomia (em sentido kantiano) à medida que eles mesmos possam compreender-se como autores das leis às quais eles mesmos estão submetidos como sujeitos privados do direito. 0 liberalismo 1 ignora a equiprocedência das autonomias privada e pública. Não se trata aí apenas de uma complementação que permaneça externa à autonomia privada, mas sim de uma concatenação interna, ou seja, conceitualmente necessária ${ }^{23}$.

\footnotetext{
${ }^{22}$ HABERM AS, Jürgen. A inclusão do outro: estudos de teoria política. São Paulo: Loyola. 2007, p. 242.
}

${ }^{23}$ Ibidem, p. 242. 
Habermas entende que, enquanto aos sujeitos não estiverem assegurado o exercício comum e conjunto da sua autonomia enquanto cidadãos do Estado, consequentemente, o desfrute das liberdades subjetivas comuns estará embaraçado, ou seja, impedido. A orientação proposta pelo filósofo alemão vem fundamentada sobre a ideia impreterível de se estabelecer uma concatenação interna entre o Estado de Direito e a Democracia; consequentemente, teremos um sistema de direito que alcançará todos os modos de vida presentes no Estado, desde aquelas vidas circunscritas no centro urbano como aquelas postas à sua margem. Sendo assim, o sistema de direito poderá ouvir as múltiplas diferenças culturais existentes e, como tal, deverá assisti-las em suas diferenças devendo prestar-Ihes respostas quando por elas for invocado ${ }^{24}$.

Em suas considerações, Honneth aponta que, por meio do reconhecimento intersubjetivo, os sujeitos podem garantir realização plena das suas capacidades, bem como chegar a uma autorrelação marcada pela integridade, ou seja, os sujeitos, dadas suas interações, recebem certa modulações, destarte, só conseguirão formar uma autorrelação positiva caso possam se sentir reconhecidos por seus parceiros de interação.

A teoria de Honneth ${ }^{25}$ observa também substrato normativo presente nas relações sociais. Sua teoria parte do princípio de que o conflito é intrínseco, portanto necessário, tanto à formação da intersubjetividade como dos próprios sujeitos. Desse modo, conflito não é tomado apenas pela lógica da autoconservação dos indivíduos, como descrito no estado de natureza de Hobbes. Seu significado tem por preceito a conotação de uma luta moral, entendendo que a organização da sociedade, necessariamente, deve estar pautada por obrigações intersubjetivas. Honneth concatenua a ideia hegeliana com a psicologia social de George H. Mead.

Mead $^{26}$ direciona suas pretensões teóricas a partir de um horizonte intersubjetivista, defendendo a existência de um diálogo interno que toma os impulsos individuais e a cultura internalizada como objeto de pesquisa, e investiga a importância das normas morais nas relações humanas. Mead situa as interações sociais como campo onde ocorrem os conflitos entre 0 eu, a cultura e os outros. O teórico norte-americano defende a gênese social da identidade e vê a evolução moral da sociedade sempre atrelada à luta por reconhecimento forjada a partir de três

\footnotetext{
${ }^{24}$ Ibidem, p. 243.

${ }^{25}$ HONNETH, A. Luta por reconhecimento: a gramática moral dos conflitos sociais. São Paulo: Ed. 34, 2003, p. 152.

${ }^{26}$ M EAD, G. H. Espiritu, persona y sociedad. Ciudad de México : Paidós. 1993, p. 97.
} 
tipos de relação: as primárias (reguladas pelo amor), as jurídicas (reconhecidas pela lei) e a esfera do trabalho onde está presente o valor do indivíduo com relação a coletividade.

A partir dessas premissas, Honneth sistematiza umateoria do reconhecimento, descrevendo que são as lutas moralmente motivadas de grupos sociais, sua tentativa coletiva de estabelecer institucional e culturalmente formas ampliadas de reconhecimento recíproco, aquilo por meio do qual vem a se realizar a transformação normativamente gerida das sociedades. Hannet entende que o descaso, o desprezo social e político podem tornar impulsos que dinamizam lutas sociais, à medida que torna evidente que outros atores impedem a realização daquilo que se entende por bem viver, ou seja, se por um lado, o rebaixamento e a humilhação ameaçam identidades, por outro, eles estão na própria base da constituição de lutas por reconhecimento. Portanto, isso significa dizer, que toda reação emocional negativa que vai de par com a experiência de um desrespeito de pretensões de reconhecimento contém novamente em si a possibilidade de que a injustiça infligida ao sujeito se lhe revele em termos cognitivos e se torne o motivo da resistência política ${ }^{27}$.

Na concepção de Habermas, essa premissa constitui-se como condição vital sine qua non para que uma teoria dos direitos, entendida de maneira correta, venha a exigir, exatamente, e assegurar o direito ao exercício da política de reconhecimento que preserva a individualidade e a integridade do indivíduo até nos contextos vitais que conformam sua identidade ou a configuram. Nesse sentido, não é preciso que se formule um modelo oposto que corrija o viés individualista do sistema de direitos sob outros pontos de vista normativos; é preciso apenas que ocorra a realização coerente desse viés. Entende Habermas que os movimentos sociais e as lutas políticas são extremamente relevantes para concretização do reconhecimento. 0 autor compreende ser necessário que se criem e disponibilizem competências jurídicas iguais das quais surgem espaços para liberdades de ação que podem ser utilizadas diferenciadamente, ou seja, não se fomenta a ideia de um formalismo irrestrito com vistas a uma igualdade factual de situações de vida ou de poder; antes, o multiculturalismo é visto de forma salutar para a manutenção das identidades coletivas, seja no contexto de uma cultura majoritária ou em meio à comunidade dos povos. Contudo, observa o filósofo que alguns pressupostos factuais devem ser cumpridos para que

${ }^{27}$ HONNETH, A. Luta por reconhecimento: a gramática moral dos conflitos sociais. São Paulo: Ed. 34, 2003, p. 224. 
"competências jurídicas sob condições de igualdade sejam distribuídas com equidade, caso se deseje evitar que o sentido normativo da igualdade de direitos se inverta por completo" ${ }^{28}$.

Essa preocupação consiste exatamente em reconstruir a constituição co-originária entre poder político e o direito, mostrando que, mediante essa relação, resulta um novo nível da tensão entre facticidade e validade, agora situada no próprio poder político. Nesse sentido, a questão da legitimação de um poder político estruturado na forma do Estado de direito pode ser compreendida desde que, por intermédio da ótica do conceito de autonomia política dos cidadãos, fundamentado na teoria do discurso, se consiga diferenciar as figuras do poder comunicativo, produto do direito legítimo, e a do poder administrativo, responsável por imposições das leis ${ }^{29}$. Para Aluisio Schumacher, a contribuição do poder político para a função intrínseca do direito (estabilizar expectativas de comportamento) consiste na geração de uma certeza jurídica, que possibilita aos destinatários do direito calcular as consequências de seu comportamento e dos outros ${ }^{30}$. As normas jurídicas, em termos gerais, devem regular as circunstâncias, as situações de fato, aplicando a sua subsunção de forma imparcial. Esses requisitos são compreendidos à luz de uma codificação (atividade jurisprudencial), que proporciona normas jurídicas altamente consistentes.

Com relação ao direito, sua contribuição à função intrínseca do poder administrativo (realizar fins coletivos) evidencia-se, especialmente, no desenvolvimento de normas secundárias, que, segundo Schumacher, não se tratam tão somente daquelas normas "que conferem poder (e até criam) às instituições governamentais, dotando-as de jurisdições especiais, como também normas organizacionais que estabelecem procedimentos para a existência e gestão administrativa ou judicial de programas jurídicos". Assim, a atividade do direito, sua função e aplicabilidade, atinge outras esferas que não somente a da atividade jurisprudência jurídica, mas alcança também

${ }^{28}$ SILVA, Luciano Braz. Considerações de Jürgen Habermas para a filosofia do direito do século XXI: Os limites e possibilidades da democracia, do Estado Democrático de Direito e, dos Direitos Humanos. Centro Universitário Eurípides de Marília. Marília, 2013, p. 83.

${ }^{29}$ WERLE, Denílson L; SOARES, M auro V. Política e direito: a questão da legitimidade do poder político no Estado Democrático de Direito. São Paulo: Malheiros. 2008, p. 130-131.

30 SCHUMACHER, Aluisio Almeida. "Comunicação e democracia: fundamentos pragmático-formais e implicações jurídico-políticas da teoria da ação comunicativa". Departamento de Ciências Política do Instituto de Filosofia e Ciências Humanas da Universidade Estadual de Campinas. Campinas, 2000, p. 242 
a esfera das instituições de governo - procedimentos e competências - garantindo, assim, a autonomia privada e pública dos cidadãos ${ }^{31}$.

Numa releitura dos séculos XX e XIX, depreende-se que alguns agentes sociais, sobretudo, o feminismo, sob fortes oposições, precisaram empreender várias investidas para fazer valer seus objetivos legais e políticos. Inicialmente, a política liberal tencionou desacoplar conquistas de status e identidade de gênero, com seus reclames e protestos - conteúdo de seus ideários: as mulheres passaram a obter igualdades de chances na concorrência por postos de trabalho, prestígio social, nível de educação formal, poder político, etc. A igualdade formal que fora alcançada parcialmente pode agregar tão somente uma fração da sociedade; com isso, evidenciaram-se, ainda mais, as desigualdades de tratamento factual a que as mulheres estavam submetidas. Nesse contexto, políticas socioestatais, voltadas à implementação dos direitos (reconhecimentos) sociais ligados ao trabalho e a família, reagiram com regulamentações especiais; por exemplo, a maternidade e os encargos sociais, em caso de divórcio. Entrementes, a crítica feminista indignou-se contra as exigências liberais não resolvidas bem como contra os programas sociais implementados com êxito que trouxeram consequências ambivalentes, como os riscos de acidentes e infecções patológicas nos ambientes de trabalho, a presença excessiva de mulheres nos cargos de baixíssima remuneração laborativa, 0 bem-estar infanto-juvenil evidentemente problematizado, a crescente "feminização" da pobreza de modo geral, etc ${ }^{32}$. Habermas aponta, ainda, um fator preponderante que corroborou diretamente para a implementação dos estereótipos de identidades de gênero: em áreas do direito feminista, o paternalismo socioestatal assume um sentido literal e, nesse sentido, o poder legislativo e a própria jurisdição passam a orientar-se conforme os modelos tradicionais de interpretação que existiam. A classificação dos papéis sexuais e das diferenças do gênero compõe as camadas elementares da autocompreensão cultural da sociedade. Com isso, considera Habermas que

Só agora 0 feminismo radical toma consciência do caráter dessa autocompreensão, que se revela falível, profundamente questionável e carente de revisão. Ele insiste, e com razão, em que se devem esclarecer junto à opinião pública de caráter político, ou seja, em um debate público acerca da interpretação

3131 SCHUMACHER, Aluisio Almeida. "Comunicação e democracia: fundamentos pragmático-formais e implicações jurídico-políticas da teoria da ação comunicativa". Departamento de Ciências Política do Instituto de Filosofia e Ciências Humanas da Universidade Estadual de Campinas. Campinas, 2000, p. 246.

32 HABERM AS, Jürgen. A inclusão do outro: estudos de teoria política. São Paulo: Loyola. 2007, p. 244. 
adequada das carências, os enfoques sob os quais as diferenças entre experiências e situações de vida de determinados grupos de homens e mulheres se tornam significativos para um uso das liberdades de ação em igualdades de chances $^{33}$.

A partir dessas considerações, Habermas acredita ser possível demonstrar, de forma clara, a transformação da compreensão paradigmática do direito que se configura ora pelas liberdades subjetivas em prol das concorrências em particular, ora mediante reivindicações de benefícios, ideário do Estado de bem-estar social. Com isso, obtemos uma concepção procedimental do direito, em que o processo democrático, a um só tempo, pode assegurar a autonomia privada e pública. Devemos considerar - a partir dos debates públicos - os aspectos relevantes para o tratamento igualitário ou desigual de casos típicos isolados, caso se queira assegurar às mulheres uma organização particular e autônoma da própria vida condizente com seus direitos subjetivos. As perspectivas fomentadas pelas lentes liberais do sistema de direitos que não considera essas relações, evidentemente, não se manterão; a não ser no entendimento errôneo do universalismo dos direitos fundamentais como nivelamento abstrato de diferenças tanto culturais como sociais. Vejamos que o sistema do direito, caso se queira tornar efetivo por via democrática, deverá considerar, de forma séria, as diferenças sociais e culturais relevantes em cada contexto ${ }^{34}$.

\subsection{A luta por reconhecimento}

Os fenômenos sociais que potencializam os sujeitos, as comunidades e as nações a lutarem por um reconhecimento, muito embora, na maioria dos casos, sejam homogêneos e ainda demonstrem características similares, como é o caso do feminismo, do multiculturalismo, do nacionalismo e a luta contra a herança eurocêntrica do colonialismo, ainda que possam demonstrar algumas semelhanças, não podem ser confundidos, dado o fato das peculiaridades essenciais. Vejamos que a semelhança nos parece evidente, pois tanto as mulheres, as minorias étnicas e culturais, como também, as nações e culturas, todas se defendem da opressão que é lançada, da marginalização e do desprezo nos quais são encerrados. A defesa desses atores sociais se constrói mediante lutas e manifestos incessantes de reconhecimento de identidades coletivas,

\footnotetext{
${ }^{33}$ Ibidem, p. 245.

${ }^{34}$ HABERM AS, Jürgen. A inclusão do outro: estudos de teoria política. São Paulo: Loyola. 2007, p. 245.
} 
seja no contexto de uma cultura majoritária, seja em meio à comunidade dos povos. Esses aguerridos manifestos sociais são movimentos que buscam sua emancipação própria voltada sempre aos seus ideários políticos coletivos definidos culturalmente ${ }^{35}$. Para Habermas, a questão do reconhecimento não afeta tão somente questões de ordem diretamente ligadas à dignidade humana, mas também considerações de ordem jurídica que comprometem diretamente carências da vida humana. Em suas palavras, Habermas aponta que:

Embora o feminismo não seja a causa de uma minoria, ele se volta contra uma cultura dominante que interpreta a relação dos gêneros de uma maneira assimétrica e desfavorável à igualdade de direitos. A diferença de situações de vida e experiências peculiares ao gênero não recebe consideração adequada, nem jurídica nem informalmente; tanto a autocompreensão cultural das mulheres quanto a contribuição que elas deram à cultura comum estão igualmente distantes de contar com o devido reconhecimento; e, com as definições vigentes, as carências femininas mal podem ser articuladas de forma satisfatória ${ }^{36}$.

A luta política por reconhecimento centra-se em discursos debatidos nos espaços públicos voltados à interpretação de interesses de realizações peculiares aos diferentes gêneros; à medida que logra êxito, essa luta modifica a identidade coletiva das mulheres e, por conseguinte, acarreta, também, algumas mudanças de relações entre os gêneros, afetando, assim, de forma imediata, a autocompreensão dos homens. Com isso, aqueles valores reconhecidos em escala na sociedade são levados para os debates discursais, de forma que, dado o caráter de relevância desses valores para sociedade, a consequência da problematização desses valores chega até as áreas centrais da vida privada e, portanto, afetam os limites estabelecidos entre as esferas pública e privada. A situação se difere quando se trata da luta das minorias étnicas e culturais pelo reconhecimento de sua identidade coletiva; já que esses movimentos de emancipação visam, também, à superação da divisão (ou separação) ilegítima da sociedade, a autocompreensão da cultura majoritária pode não sair ilesa. Nas sociedades multiculturais os movimentos de emancipação não representam, resumidamente, fenômenos unitários. Isso significa dizer que eles se diferenciam de acordo com as diversas situações; por exemplo, as minorias endógenas -

${ }^{35}$ SILVA, Luciano Braz. Considerações de Jürgen Habermas para a filosofia do direito do século XXI: Os limites e possibilidades da democracia, do Estado Democrático de Direito e, dos Direitos Humanos. Centro Universitário Eurípides de Marília. M arília, 2013, p. 89.

${ }^{36}$ HABERM AS, Jürgen. A inclusão do outro: estudos de teoria política. São Paulo: Loyola. 2007, p. 246. 
considera o autor - "podem tornar-se conscientes de sua identidade" ou, por conta da imigração, poderão surgir novas minorias, e, mesmo assim, esse fenômeno ocorrerá com as políticas culturais de alguns Estados que se autocompreendem como Estados de migração, cabendo, essa tarefa de emancipação também aos Estados, cuja autocompreensão nacional dependa de uma adaptação à integração de culturas estrangeiras ${ }^{37}$.

Outra distinção abordada por Habermas diz respeito ao novo tipo de nacionalismo que trata daquelas populações que compartilham entre si um destino histórico comum. Essas populações identificam e organizam-se em grupos étnicos linguisticamente homogêneos e, como tal, desejam manter sua identidade não apenas como comunidades ascendentes comuns, mas também sob a forma de um povo que se organiza como Estado e possui autonomia política. 0 modelo de movimentos nacionais, considerado por Habermas:

(...) quase sempre foi o Estado nacional constituído por via republicana, tal como surgiu da Revolução Francesa. A Itália e a Alemanha, em comparação com os Estados nacionais da primeira geração, foram chamadas "nações tardias". Outro contexto foi dado pelo período de descolonização após a Segunda Guerra Mundial. Outra constelação, por sua vez, é dada pela decadência de impérios como o Reino Otomano, a Áustria-Hungria ou a União Soviética ${ }^{38}$.

Disso se distinguem algumas situações de minorias nacionais que surgiram em virtude da formação de Estados nacionais, por exemplo, os bascos, curdos e irlandeses do norte. Um caso especial identificado por Habermas é a fundação do Estado de Israel, sua instituição fora em decorrência de movimentos nacional-religiosos e dos horrores humanos ocorridos em Auschwitz, na região da Palestina, inicialmente de mandato inglês e reivindicado por árabes ${ }^{39}$.

Em nível internacional, a luta por reconhecimento surgiu em decorrência do eurocentrismo e do predomínio da cultura ocidental no campo político mundial, ambos vistos por Habermas como condições essenciais para uma luta por reconhecimento em nível internacional. 0 filósofo aponta a Guerra do Golfo como um fato que tornou consciente essa dimensão. A percepção daquilo que ocorrera, os motivos políticos, os interesses camuflados, se deram às sombras de uma história colonial ainda presente, a intervenção dos aliados foi vista por massas

\footnotetext{
${ }^{37}$ Ibidem, p. 247.

${ }^{38}$ HABERM AS, Jürgen. A inclusão do outro: estudos de teoria política. São Paulo: Loyola. 2007, p. 248.

${ }^{39}$ Ibidem, p. 248.
} 
religiosamente mobilizadas e também por intelectuais secularizados como abuso da identidade e autonomia do mundo arábico-islâmico ${ }^{40}$. Os vestígios, as marcas indeléveis dessas lutas fracassadas de reconhecimento marcam, até hoje, as relações históricas (a economia, a política, a religião, as relações de direitos humanos, etc.) entre Ocidente e Oriente e, tanto mais, 0 relacionamento do Primeiro Mundo com o Terceiro, como antes era chamado.

No debate sobre political correctness, fenômeno apontado por Habermas que ocasionou, em primeiro lugar, um autoentendimento entre os intelectuais norte-americanos sobre o status da modernidade, o que, para os radicais, significa um avanço entusiasta rumo à pósmodernidade e à remoção de figuras de pensamento totalizadoras, para os tradicionais seria 0 sinal de uma crise que só poderá ser superada por um persistente regresso às tradições clássicas do ocidente. Num outro plano mais elaborado, situam-se os discursos filosóficos em sentido estrito, que consideram, de sobremodo, os problemas já referidos e os toma como ponto de partida para descrever os problemas de ordem geral. Esses fenômenos prestam-se aos esclarecimentos e às considerações explícitas quanto à dificuldade do acordo mútuo intercultural; eles esclarecem a relação entre moral e eticidade, ou uma interligação entre significação e validação, e reacendem a velha questão sobre podermos transcender o contexto de nossa respectiva língua e cultura ou, ao contrário, todos os padrões de racionalidade estarão atrelados a determinadas imagens de mundo e determinadas tradições ${ }^{41}$. Com suas palavras, Habermas aponta que

As esmagadoras evidências da fragmentação de sociedades multiculturais e da confusão linguística babilônica em meio a uma sociedade mundial mais que complexa parecem compelir-nos a concepção holística de linguagem e a concepção contextualísticas de imagens de mundo que soam céticas em face de tantas reivindicações universalistas, sejam elas de natureza cognitiva ou normativa ${ }^{42}$.

0 autor ainda nos mostra que 0 debate sobre a realidade, ramificado e aberto até há pouco tempo, é de vital importância tendo em vista que seus resultados trazem consequências

\footnotetext{
${ }^{40}$ Ibidem, p. 249.

${ }^{41}$ SILVA, Luciano Braz. Considerações de Jürgen Habermas para a filosofia do direito do século XXI: Os limites e possibilidades da democracia, do Estado Democrático de Direito e, dos Direitos Humanos. Centro Universitário Eurípides de Marília. Marília, 2013, p. 97.

${ }^{42}$ HABERM AS, Jürgen. A inclusão do outro: estudos de teoria política. São Paulo: Loyola. 2007, p. 250.
} 
que tocam diretamente as considerações apresentadas em torno dos conceitos de bom e justo com os quais lidamos ao investigar as condições de uma política do reconhecimento. Nesse sentido, uma sugestão apontada por Taylor, em si mesma, remete-se a outra coisa; ela está embasada - considera Habermas - no plano de referências do direito e da política.

Nesse sentido, o problema do direito ou direitos de minorias ofendidas e maltratadas passa a ser um problema de ordem jurídica e, como tal, deve ser resolvido. No Estado de direito, decisões políticas não podem infringir normas do direito positivo, ou seja, as decisões políticas, para que sejam validas, deverão se servir das regulamentações do direito positivo para tornaremse efetivas em sociedades complexas. Destarte, o médium do direito aponta para uma estrutura artificial onde decisões normativas prévias se relacionam. Verificamos, portanto, que o direito moderno em sua estrutura é identificado como formal e se embasa na premissa de que tudo não seja explicitamente proibido e permitido. 0 direito moderno reconhece, individualmente, cada pessoa como sujeito portador de direitos subjetivos; nesse sentido, como titulares de uma categoria de direitos, esses mesmos sujeitos podem - valendo-se desses direitos - tutelar judicialmente, contra particulares ou até mesmo contra o Estado, direitos que lhes subtraíram ${ }^{43}$. Nas palavras de Habermas, o direito moderno é identificado como

Um direito coercivo porque sanciona de maneira estatal e estende-se apenas ao comportamento legal ou conforme normas - ele pode, por exemplo, tornar livres as religiões, mas não pode prescrever nenhuma consciência moral. É um direito positivo porque retroage às decisões - modificáveis - de um legislador político, e é, finalmente, um direito escrito por via procedimental, já que legitimado mediante um procedimento democrático ${ }^{44}$.

O direito moderno - positivo - muito embora regule comportamentos legais, ainda assim, para sua validade, deve ser reconhecido como legítimo. Não obstante seu reconhecimento, respeito e obediência por todos, o direito moderno deve ser reconhecido de maneira que também possa ser cumprido a qualquer momento por seus destinatários, pelo simples respeito à lei. Para Habermas, uma ordem jurídica é definida como legítima quando assegura, de forma equitativa, a autonomia de todos os cidadãos. Esta autonomia estará concretamente constituída no instante em que destinatários do direito entenderem-se como seus autores e destinatários. Tais autores

\footnotetext{
${ }^{43}$ Ibidem, p. 250.

${ }^{44}$ Ibidem, p. 251.
} 
então, como participantes do processo legislativo, serão livres tão somente se esse processo estiver regrado por atos de fala discursivos e, necessariamente, democráticos, em que todos possam supor que as regras foram (ora?) firmadas e, desse modo, mereçam concordância geral sancionada pela razão. Por entendimento, faz-se menção a um processo discursivo racional que leva os sujeitos ao convencimento objetivado entre as partes. Esse processo coordena as ações de fala de todos os participantes por meio da razão que vale como motivação e regularização, sendo que as ações de fala são utilizadas como meio para se chegar ao convencimento e, por conseguinte, ao consenso. Desse modo, entendimento é o "processo de obtenção de um acordo entre sujeitos linguística e inteiramente competentes" ${ }^{45}$. No núcleo da linguagem há, algumas estruturas básicas dominadas pelo sujeito em determinados momentos da vida. Enquanto sujeito, no processo de formação do indivíduo, a consciência é um dos atributos que ele recebe, ou seja, a capacidade reflexiva adquirida mediante suas ações no mundo, o que o torna capaz de concebê-lo individualmente ou, em outras palavras, de uma forma peculiar. Logo, por meio da linguagem, sua ação prioriza o discurso racional como condição para se chegar à veracidade da fala de um sujeito e analisar se a fala é coerente ou não com a ação; nesse sentido, poderá convertê-la em normas revalidadas, compreendidas e aceitas por todos. A estrutura básica da ação comunicativa vinculase, em geral, a três pretensões objetivas pelos integrantes do mundo da vida, a saber: 1) pretensão de verdade: que corresponde à pretensão de que o enunciado seja verdadeiro - essa pretensão refere-se a afirmações e acontecimentos oriundos do mundo objetivo; 2) pretensões de justiça: os atos de fala, necessariamente, devem estar em sintonia com o contexto normativo vigente - faz-se alusão ao mundo social ou ao mundo das normas legitimamente reguladas e, 3) pretensão de veracidade: ocorre quando a intenção expressa na fala do indivíduo corresponde a seu pensamento - trata-se, especificamente, do mundo subjetivo do indivíduo ${ }^{46}$.

A partir dessa formulação, o conceito tradicional de razão prática adquire um valor heurístico: ele se torna fio condutor para reconstrução do emaranhado dos discursos; consequentemente, a concepção normativa que interpreta o direito, mormente filiado à moral passa a ser recusado na filosofia habermasiana. 0 processo democrático deve ser

\footnotetext{
${ }^{45}$ HABERM AS, Jürgen.Teoria de la acción comunicativa. Racionalidad de La acción y racionalización social. Madrid: Taurus, 1987, p. 368.

${ }^{46}$ PENITENTE, Luciana Aparecida de Araújo. Habermas e M ead: A linguagem como M édium de Socialização. Marilia: Oficina Universitária Unesp, 2008. P. 99.
} 
institucionalizado juridicamente, o princípio da soberania dos povos exige o devido respeito a direitos fundamentais sem os quais, simplesmente, não pode haver um direito legítimo. Nesse sentido, Habermas fala, em primeira linha, do direito a liberdades de ações subjetivas iguais que, por sua vez, pressupõem defesas jurídicas individuais e abrangentes. Com a instituição do Estado de direito e o reconhecimento dos direitos subjetivos dos indivíduos, há consequências salutares para o tratamento do problema da isonomia jurídica e do igual reconhecimento de grupos culturalmente definidos, ou seja, de coletividades que se distinguem de outras - seja pela tradição, forma de vida, proveniência étnica, etc ${ }^{47}$.

\section{JUSTIFICAÇÃO PROCESSUAL DO ESTADO CONSTITUCIONAL DEM OCRÁTICO COM BASE NOS DIREITOS HUM ANOS}

A proposta de Habermas que busca perquirir a legitimidade do Estado constitucional democrático com base nos direitos humanos visa a estabelecer uma conexão interna entre a democracia e os direitos humanos. Para tanto, Habermas entende ser necessário que se formule um conceito político de legitimação de ordens caracterizadas pela organização do poder estatal, que segue atrelado ao conceito de potência política. Considerando que esse médium da potência estatal se constitui sob a forma do direito, as ordens políticas buscam, na legitimidade reivindicada do direito, seu vigor. Portanto, o direito reivindica não apenas aceitação; ele demanda dos seus endereçados não apenas um reconhecimento fático; antes, protesta pelo seu devido reconhecimento. Daí porque todas as instituições públicas, por pertencerem à ordem estatal e, como tal, seguem investidas da legitimidade legal, devem manifestar a base para essas reivindicações ${ }^{48}$.

Assim, não causa espanto que as teorias do direito racional tenham dado uma dupla resposta às questões de legitimação: por um lado, pela alusão ao princípio da soberania popular, e por outro lado, pela referência ao domínio das leis garantido pelos direito humanos ${ }^{49}$.

\footnotetext{
${ }^{47}$ HABERM AS, Jürgen. A inclusão do outro: estudos de teoria política. São Paulo: Loyola. 2007, p. 257. . A constelação pós-nacional: Ensaios políticos. São Paulo: Littera M undi, 2001, p. 143144.

49 A inclusão do outro: estudos de teoria política. São Paulo: Loyola. 2007, p. 298.
} 
Para 0 filósofo, esse argumento vale em todas as ordens estatais. Os Estados modernos se estruturam a partir do direito positivo, que confere legitimidade à autoridade e ao mando político, ou seja, as regulamentações do Estado que coagem seus transgressores reclamam a legitimidade oriunda do médium regulador do direito. As ordens jurídicas modernas conservamse, essencialmente, daquilo que Ihes é posto pelos direitos subjetivos. Com isso, entende-se que à pessoa jurídica individual the são asseguradas âmbitos legais para uma ação guiada tão somente por seus interesses particulares preferências. Dessarte, esses direitos desconectam, de modo claro, as pessoas dos mandamentos morais ou das prescrições de outros gêneros. Sendo assim, dentro das limitações instituídas pela lei, ninguém é juridicamente obrigado a uma justificação pública dos seus atos. Com a implantação de liberdades subjetivas, o direito moderno, diferentemente das ordens jurídicas tradicionais, remonta ao princípio hobbesiano, segundo 0 qual é permitido tudo aquilo que não é explicitamente proibido. Desse modo, ocorre um hiato entre a moral e o direito. Enquanto a moral, a priori, nos diz a que somos obrigados, resulta da estrutura do direito um primado das autorizações àquilo que podemos fazer ${ }^{50}$. Nesse sentido, os direitos morais são concebidos a partir das obrigações recíprocas, enquanto as obrigações jurídicas o são da delimitação legal das liberdades subjetivas. Como predicado desses conceitos, formula-se a identidade da comunidade jurídica - sempre localizada no espaço e no tempo - que reconhece seus membros como portadores de direitos subjetivos, por conseguinte, a integridade de todos seus membros - que aceitam, reciprocamente, esse status - está protegida pelo direito então vigente. Essa estrutura reflete-se no modo característico da validade jurídica que limita a facticidade da execução judicial estatal com a legitimidade de uma positivação jurídica que reivindica o status de um procedimento racional ${ }^{51}$.

Quando se introduz o direito (em geral) como complemento ao déficit da moral, a facticidade da normatização e do império do direito, bem como a autoaplicação construtiva do direito, assumem um caráter constitutivo para um determinado tipo de interação destituída de conteúdo moral. Portanto, o médium do direito pressupõe uma categoria de direitos (fundamentais) que definem 0 status de pessoas jurídicas como portadoras de direitos em geral. 0 sistema de direito deve, precisamente, conter os direitos que os cidadãos, de modo recíproco, estão obrigados atribuir uns aos outros, caso queiram regular, legitimamente sua convivência com

\footnotetext{
${ }^{50}$ HABERM AS, Jürgen. A constelação pós-nacional: Ensaios políticos. São Paulo: Littera M undi, 2001, p. 144.
} ${ }^{51}$ Ibidem, p. 144-145. 
os meios do direito positivo. As regras do direito positivo não regulam possíveis interações formuladas por sujeitos capazes de falar e de agir; em geral, esses atos são regulados pela regra da moral. As regras do direito regulam as ações interacionais de uma sociedade concreta como corolário do próprio conceito de positividade do direito, ou seja, da facticidade da normatização e da imposição da normatividade do próprio direito ${ }^{52}$.

Habermas entende que o direito moderno, com efeito, deixa seus endereçados livres para observarem as normas apenas como uma restrição fática do seu âmbito de ação e, a partir daí - diante de uma situação onde há violação às regras impostas pelo direito -, se ajustarem a um relacionamento estratégico, sobrepesando, mensuravelmente, as consequências que poderão advir ou obedecerem à lei tão somente em obediência a seus ditames. Essa dicotomia remonta ao pensamento kantiano, com seu conceito de legalidade, destacando a ligação entre esses dois momentos sem os quais não se pode exigir obediência jurídica das pessoas moralmente responsáveis. Segundo o filósofo, as normas jurídicas, quando elaboradas, devem ser apresentadas, concomitantemente, sob dois aspectos, a saber: como leis coativas e como leis da liberdade. Portanto, isso significa dizer que, no mínimo as normas jurídicas devem ser respeitadas não somente porque elas coagem, mas sim porque elas são legítimas ${ }^{53}$. Sendo assim, a legitimidade de uma norma jurídica afirma que o poder estatal garante, ao mesmo tempo, positivação jurídica legítima e execução judicial fática. Com isso, no entanto, a obrigatoriedade das normas jurídicas remonta não apenas a processos de formação de opinião e vontade, mas sim a decisões coletivamente vinculativas, por instâncias que estabelecem e aplicam o direito. Resulta daí, de maneira conceitualmente necessária, uma partilha de papéis entre autores que afirmam (e enunciam) 0 direito, bom como entre os destinatários que estão submetidos ao direito vigente ${ }^{54}$.

Com relação à legitimidade da ordem jurídica, Habermas traz uma observação de ordem formal em que considera importante, a saber, a positividade do direito positivado. Essa observação segue atrelada à arguição, formulada pelo filósofo, quanto à legitimidade, e sua fundamentação, de regras que podem ser mudadas a todo momento pelos legisladores políticos. Ora, é sabido que também normas constitucionais são alteradas, assim como as normas fundamentais que a própria constituição declara como pétreas, ou seja, inalteráveis; essas normas

52 . Era das transições. Rio de Janeiro: Tempo Brasileiro, 2003, p. 153-154.

${ }_{53}^{53}$ HABERM AS, Jürgen. A constelação pós-nacional: Ensaios políticos. São Paulo: Littera M undi, 2001, p.145.

A inclusão do outro: estudos de teoria política. São Paulo: Loyola. 2007, p. 298. 
compartilham com o todo do direito positivado e, assim sendo, podem ser desativadas, por exemplo, após a mudança de um governo.

3.1. Soberania popular: deliberações, assentimentos, processos cognitivos e legitimidade procedimental

Em primeiro lugar, Habermas considera que só podem ser tomados por legítimos os processos nos quais os sujeitos, livremente, se reúnem em torno de algo para deliberarem. Isso significa dizer que os participantes não serão conduzidos por algo externo ao seu intento, enquanto agentes de atos de fala discursiva racionalmente fundamentada, todavia isso não exclui a possibilidade do falibilismo, pois a busca pela resposta unívoca não garante, por si mesma, um resultado correto. Para o filósofo "somente o caráter discursivo do processo de deliberação é capaz de fundamentar a possibilidade de autocorreções reiteradas e, destarte, a perspectiva de resultados racionalmente aceitáveis". Em segundo lugar, os participantes devem comprometer-se, por meio de um questionamento específico, e tomar o direito moderno como médium para regular suas convivências. Da legitimação empregada ao consentimento geral obtido sob condições do discurso democrático, vinculado às leis obrigatórias que abrem espaços para iguais liberdades subjetivas, remonta ao conceito kantiano da ideia de autonomia política: "aqui ninguém é livre, enquanto houver um único cidadão impedido de gozar da igual liberdade sob leis que todos os cidadãos se deram a si mesmos, seguindo uma deliberação racional" 55 .

Para uma compreensão válida sobre o sistema dos direitos fundamentais, cumpre analisarmos, de antemão, algumas objeções quanto à tentativa procedimentalista de combinar a ideia dos direitos humanos com o princípio da soberania do povo. Dada a relevância dessas objeções, mister se faz obter clareza sobre as consequências da proposta que busca explicar a forma do Estado de direito democrático sob o viés da institucionalização jurídica de uma ampla rede de discursos. Por uma questão lógica, os discursos públicos passam a ser especificados em detrimento do objeto no qual são formulados e, sendo assim, há de se considerar, também, 0 tempo e o contexto social, tendo em vista a formação política da opinião e da vontade em espaços públicos e nas corporações legislativas, bem como nos atos jurídicos e administrativos decisórios. Ainda nas considerações observadas por Habermas, a visão de Michelman dirige-se para esta

${ }^{55}$ HABERM AS, Jürgen. Era das transições. Rio de Janeiro: Tempo Brasileiro, 2003, p. 162. 
dimensão da regulação jurídica; por conseguinte, abrange tanto os direitos fundamentais e políticos, passando pelas determinações da parte organizacional da constituição, alcançando os direitos procedimentais e as ordens do dia de corporações. Vê Habermas que Michelman aponta para a dimensão do estabelecimento de formas de comunicação, sabendo que a prática constituinte não pode ser reconstruída conforme critérios da teoria do discurso, pois, certamente, chegar-se-ia a um processo circular infindável. Ora, um processo democrático confiável é, necessariamente, um processo continuado e condicionado legalmente por leis que buscam uma representação política por associações civis e familiares, o direito à liberdade de fala, à propriedade, 0 acesso à mídia. Dessarte, as leis que tratam desses objetos devem ser constituídas por meio de procedimentos válidos, politicamente democráticos, sem distorções, não somente nos ambientes estatais, mas, também, nas redes da sociedade como um to do ${ }^{56}$.

Graças a esse sentido performativo disponível para cada cidadão ligado a uma comunidade política democrática, cada um pode contribuir, à sua maneira, para explicar o que significa perseguir e concretizar o projeto de uma associação de sujeitos livres e iguais que se autodeterminam. Destarte, qualquer ato fundador abre possibilidades a um processo ulterior que se autocorrige reestruturando as fontes do sistema de direito. A interpretação discursiva da autoconstituição democrática do Estado constitucional exige ainda, que demonstremos como os princípios democráticos são inerentes à constituição da democracia enquanto tal. Devemos explicar em que sentido os direitos fundamentais, em sua totalidade, são constitutivos para 0 processo da autolegislação, o que suplantaria a suposta objeção paradoxal estante entre democracia e Estado de direito.

Num primeiro momento, os participantes compreendem que, para realizar seu projeto pelo caminho do direito, há que se criar uma ordem de status, de forma que todo e qualquer cidadão e, até mesmo aqueles que irão engajar-se futuramente ao projeto, serão reconhecidos como portadores de direitos subjetivos. Tal ordem de direito positivo e obrigatório com traços subjetivistas, será concretizada desde que sejam introduzidos os direitos fundamentais de conteúdo concreto variável, (I) que resultam da configuração autônoma do direito e que asseguram as liberdades subjetivas para cada um, (II) que resultam da configuração autônoma do status de membro de uma associação livre de parceiros do direito, (III) que resultam da 
configuração autônoma do igual direito de proteção individual. Nesse sentido, reflete Habermas que essas três modalidades de direito são fundamentais para a constituição de uma associação de parceiros jurídicos que se reconhecem, reciprocamente, como portadores de direitos subjetivos reclamáveis. Por conseguinte, para sua instituição, ainda se faz necessário que se introduza uma nova categoria de direitos fundamentais: direitos fundamentais (de conteúdo concreto variável) que resultam da configuração autônoma do direito, visando a assegurar uma participação em igualdade de condições na esfera da legislação política ${ }^{57}$. Assim, o princípio democrático somente pode ser concretizado no mundo dos fatos desde que haja, efetivamente, o Estado de direito, pois ambos os princípios se locupletam reciprocamente numa relação de implicações materiais congênitas.

\section{CONSIDERAÇÕES FINAIS}

0 conceito habermasiano do agir comunicativo, que estabelece o entendimento linguístico como premissa fundamental para o mecanismo de coordenação da ação, faz com que as suposições contrafactuais dos atores, que orientam seu agir por pretensões de validade, adquiram relevância imediata para a construção e a manutenção das ordens sociais. Com isso, Habermas pretende demonstrar como a tensão entre facticidade e validade - inerente à linguagem - está pragmaticamente interligada (simbiose) com a integração de indivíduos socializados comunicativamente. Do entendimento linguístico sucede a manutenção das ordens sociais subjacentes ao reconhecimento de pretensões de validade normativa que advêm da ligação dos atos ilocucionários de fala reconhecidos mutuamente. Nossas ações de fala situam-se em um mundo da vida compartilhado intersubjetivamente que, mediado por um pano de fundo consensual, nos possibilita um entendimento prévio sobre algo. Avalia Habermas que, em qualquer ação de fala, são levantadas pretensões criticáveis que apontam para o reconhecimento intersubjetivo.

Na filosofia habermasiana, o mundo da vida ocupa posição central na coordenação e estabilização da ação social, constituindo o pano de fundo do agir comunicativo, um horizonte para situações de fala e uma fonte de interpretações para os atores que agem comunicativamente. Entretanto, o direito não é impositivo por uma questão de ordem formal, ou

${ }^{57}$ HABERM AS, Jürgen. Direito e democracia: entre facticidade e validade. Rio de Janeiro: Tempo Brasileiro. 2003, p. 168-169. 
seja, não é um direito imposto por quem detém o poder. 0 direito legítimo se configura a partir do seu desempenho como médium linguístico entre os diferentes âmbitos de ação, de forma que sua normatividade resulte não somente da sanção do Estado, mas também da observância concretizada por parte dos atores sociais. Nesse tipo de interação, os interlocutores não utilizam a linguagem 'perlocutoriamente', em outras palavras, visando instigar outros sujeitos para um comportamento desejado, mas 'ilocutoriamente', isto é, com vistas ao estabelecimento não coercitivo de relações intersubjetivas. Com isso, eles podem alterar ou sustentar fragmentos dessa rede simbólica que os precede, já que o poder-dizer-não instaura uma fratura deontológica.

É justamente no uso da racionalidade comunicativa que Habermas deposita suas esperanças. Como atesta Honneth, "Habermas deu uma guinada na tradição da teoria social crítica, na medida em que transferiu o potencial emancipatório, transcendente, da prática do trabalho para 0 modelo de ação da interação linguisticamente mediada" ${ }^{158}$. Importante destacar que, no viés habermasiano, a dominação e a subordinação não são meros reflexos da lógica instrumental-estratégica. Esta não seria, por si só, negativa, sendo mesmo necessária no campo do trabalho. 0 problema é quando as formas estratégicas de ação começam a interferir em âmbitos que devem ser regidos pelo medium da linguagem, tecnificando-os. Nesses casos, dar-se-iam os processos decolonização do mundo da vida: "mecanismos sistêmicos suprimem formas de integração social, mesmo nas áreas em que a coordenação dependente do consenso não pode ser substituída, ou seja, onde a reprodução simbólica do mundo da vida está em questão" ${ }^{59}$. Para impedi-la, Habermas aposta na dimensão moral da política, proveniente da troca comunicativa intersubjetiva. Honneth ${ }^{60}$ salienta esse aspecto quando coloca que, na obra de Habermas, "o potencial moral da comunicação é o motor do progresso social, indicando, ao mesmo tempo, sua direção".

A força da noção de intersubjetividade, presente nos três autores aqui em tela, acaba por conduzi-los a uma compreensão ampliada da política, chamando a atenção para a participação dos cidadãos em suas vidas cotidianas. Diferentemente da tradição que remonta a Weber e

\footnotetext{
${ }^{58}$ HONNETH, A. Luta por reconhecimento: a gramática moral dos conflitos sociais. São Paulo: Ed. 34, 2003, p. 246.

${ }^{59}$ HABERMAS, Jürgen.Teoria de la acción comunicativa. Racionalidad de La acción y racionalización social. Madrid: Taurus, 1987, p. 196.

${ }^{60}$ HONNETH, A. Luta por reconhecimento: a gramática moral dos conflitos sociais. São Paulo: Ed. 34, 2003, p. 242.
} 
Luhmann, que veem a política como um campo especializado e autopoiético. Habermas, Honneth e Taylor buscam compreender os processos de produção de decisões coletivas na perspectiva dos participantes e não apenas na do observador, de modo que, a dimensão moral e intersubjetiva da política não pode ser ignorada. Como objeto de pesquisa (a dominação e a emancipação nas sociedades hodiernas), eles buscam diagnosticar as patologias contemporâneas da vida política e social - traduzidas em termos de desrespeito (Honneth) ou de injustiça (Fraser). A partir dessas premissas, propõem uma gramática moral como proposta de superação. Tal como Habermas, e seu antecessor Hegel, Honneth, Fraser e Taylor perceberam que a política não se restringe a uma luta de interesses com vista à uma ação estratégica, ou seja, há horizontes normativos situados na esfera coletiva simbolicamente atualizados sobre os quais os sujeitos se apoiam. Tais horizontes estão na base de reivindicações levantadas contra formas de opressão ou desrespeito; o que explicita a permanente tensão entre a facticidade da vida social e sua normatividade observada por Jürgen Habermas.

\section{REFERÊNCIAS}

CHAMON J. Lúcio Antonio. Filosofia do direito na alta modernidade: Incursões teóricas em Kelsen, Luhmann e Habermas. Rio de Janeiro: Lúmen Júris, 2005.

DURÃO, Aylton Barbieri. A tensão interna entre facticidade e validade no direito segundo Habermas. (Org), M ARTINS, Clélia Aparecida, e POKER, José Geraldo. O pensamento de Habermas em questão. Marília: Oficina Universitária Unesp, 2008.

HABERMAS, Jürgen. A inclusão do outro: estudos de teoria política. 3. "ed.". "Tradução: Paulo AstorSoethe". São Paulo: Loyola. 2007.

. Mudança estrutural da esfera Pública. 2. "ed.". "Tradução: Flávio R. Kothe". Rio de Janeiro: Tempo Brasileiro. 2003.

Direito e democracia: entre facticidade e validade. I. 2. "ed.". "Tradução: Flávio Beno Siebeneichler". Rio de Janeiro: Tempo Brasileiro. 2003.

Tempo Brasileiro, 2003.

Era das transições. "Tradução: Flávio BenoSiebeneichler". Rio de Janeiro:

- A constelação pós-nacional: Ensaios políticos. "Tradução: Márcio Seligmann Silva". São Paulo: Littera M undi, 2001. 
- Teoria de la acción comunicativa. Racionalidad de La acción y racionalización social. Trad. M anuel Jimenez Redondo. Tomo I. Madrid: Taurus, 1987.

HONNETH, A. Luta por reconhecimento: a gramática moral dos conflitos sociais. Trad: Luiz Repa. São Paulo: Ed. 34, 2003.

M ATTOS, P. Recognition, between Justice and Identity. São Paulo: Lua Nova. 2004

MEAD, G. H. Espiritu, persona y sociedad. Ciudad de México : Paidós. 1993.

M OREIRA, Luiz. Fundamentação do direito em Habermas. Belo Horizonte: M andamentos, 1999.

PENITENTE, Luciana Aparecida de Araújo. Habermas e Mead: A linguagem como Médium de Socialização. (Orgs). Clélia Aparecida Martins e José Geraldo Poker. 0 pensamento de Habermas em questão. Marilia: Oficina Universitária Unesp, 2008.

SCHUM ACHER, Aluisio Almeida. "Comunicação e democracia: fundamentos pragmático-formais e implicações jurídico-políticas da teoria da ação comunicativa". 2000. 245 f. Tese (Doutorado em Ciências Política). Departamento de Ciências Política do Instituto de Filosofia e Ciências Humanas da Universidade Estadual de Campinas. Campinas, 2000.

SILVA, Luciano Braz. Considerações de Jürgen Habermas para a filosofia do direito do século XXI: Os limites e possibilidades da democracia, do Estado Democrático de Direito e, dos Direitos Humanos. Dissertação (Mestrado em Filosofia do Direito). Mestrado em Direito. Centro Universitário Eurípides de Marília. M arília, 2013.

SOUZA, J. Charles Taylor e a teoria crítica do reconhecimento. Brasília: UnB, 2000. . Uma teoria crítica do reconhecimento. São Paulo: Lua Nova, 2000.

TAYLOR, C. The Politics of Recognition. In : GUTMANN, A. (ed.). Multiculturalism : Examining the Politics of Recognition. Princeton : Princeton University. 1994

As fontes do self: a construção da identidade moderna. Tradução de Adail U. Sobral; Dinah de A. Azevedo. São Paulo: Loyola, 1997.

WERLE, Denílson L; SOARES, Mauro V. Política e direito: a questão da legitimidade do poder político no Estado Democrático de Direito. (Org.) Marcos Nobre, e Ricardo Terra. Direito e democracia: Um guia de leitura de Habermas. São Paulo: Malheiros. 2008. 